\title{
The Use of Pirated Software among Information Professionals: Measuring the Difference
}

\author{
Norizan Anwar (Corresponding author) \\ Faculty of Information Management, Puncak Perdana Campus \\ 40150, Universiti Teknologi MARA, Shah Alam, Selangor, Malaysia \\ Tel: 60-19-234-5700Ｅ-mail: norizananwar@gmail.com
}

Mohd Mursyiddin Abdul Manaf

Faculty of Communication \& Media Studies

40450, Universiti Teknologi MARA, Shah Alam, Selangor, Malaysia

Tel: 60-12-345-1400Ｅ-mail: iddin@salam.uitm.edu.my

\section{Noraizan Amran}

Faculty of Information Management, Puncak Perdana Campus

40150, Universiti Teknologi MARA, Shah Alam, Selangor, Malaysia

Tel: 60-19-208-4038Ｅ-mail: noraizan@salam.uitm.edu.my

\author{
Farrah Diana Saiful Bahry
}

Faculty of Information Management, Puncak Perdana Campus 40150, Universiti Teknologi MARA, Shah Alam, Selangor, Malaysia

Tel: 60-19-208-4038 E-mail: farrahdiana@salam.uitm.edu.my

Received: September 4, 2014 Accepted: December 3, 2014 Published: February 1, 2015 doi:10.5296/jmr.v7i2.6946

URL: http://dx.doi.org/10.5296/jmr.v7i2.6946

\section{Abstract}

Not millions but billions of dollars lost by software house companies due to software piracy 
issue. The numbers keep increasing year-by-year. Though there are continuous research work being done and reported across the world, nothing has been done to curb the phenomena and what should be done to make piracy to stop? Hence, this study was conducted to investigate whether there were any significant differences on this issue among information professionals in Malaysia. Factors measuring the study were Impression Management (IM), Personal Attributes (PA), Degree of Hardcore Pirate (DHP), Pirating Behavior (PB), Reciprocal Fairness (RF), Procedural Fairness (PF), Perceptions (P), Subjective Norms (SN), Intention (I) and Ethical Standards (ES). The findings of this research showed that some of the factors has significant difference and some are not. To practitioners and researcher, the findings should be able assist and guide which area and factors that need and required extra attention in order to reduce piracy issue.

Keywords: Challenge software piracy; Information professionals, Information management, Malaysia, Measurement 


\section{Introduction}

Software piracy is no longer regarded as trifling issue as it has digress to become a global matter that has been discussed my many researchers around the globe. This can be seen as many similar articles and research being published pertaining to the matter. Several prominent bodies such Business Software Alliance and etc. continuously report related topic covering the use, installation, total lost among software house companies etc. globally.

Whenever, individual install and use unlicensed illegal copy of certain proprietary software, it's considered software piracy no matter how they get it, whether its being downloaded from the internet, bought it illegally or transferred from friends. With the demand to complement daily productivy, students and information professionals are the group that potentially, highly and easily been influenced to use pirated software as per several research conducted by (Loch \& Conger, 1996; Mastura, Thurasamy \& Tee, 2008; Haque, Rahman \& Khatibi, 2010 and Anwar, Bahry \& Amran, 2012).

Factors that are being measured in this study is adapted and adopted from studies that was being conducted by Liu \& Fang, 2003; Becker \& Ulstad, 2007; Siegfried, n.d.; Hinduja, 2003; Namlu \& Odabasi, 2007 and Anwar, Bahry \& Amran, 2012. The factors measured in this study were Impression Management (IM), Personal Attributes (PA), Degree of Hardcore Pirate (DHP), Pirating Behavior (PB), Reciprocal Fairness (RF), Procedural Fairness (PF), Perceptions (P), Subjective Norms (SN), Intention (I) and Ethical Standards (ES).

With the above statement, this study aims to identify the difference on factors that influence software piracy across position hold among information professionals.

\section{Literature Review}

In the era of highly technological dependency, people are now highly dependent and widely use smartphone, tablets and computers. As discussed by (Hinduja, 2003), with those among pro-social benefits of the technology have become a variety of antisocial consequences, particularly in recent years. Due to that, there are more and more unethical and criminal activities involving computers has existed.

This software piracy issue usually related with the issues within computer ethics which has captured more than it's should be. That is why, this software piracy issue is almost as old as the existence of desktop computer. Therefore, attitudes issue among students regarding software piracy has been the subject of several studies (Siegfried, n.d.).

Similar opinion and stand by (Namlu \& Odabasi, 2007), any computer professionals shall play a role in determining how computers able to affect their social life and plus the interaction. Therefore they should be equipped with the knowledge of appropriate computer behavior in order to avoid from using any pirated software.

In addition to the above, (Liu \& Fang, 2003) mention in their study that Intention may also causing factor of behavior. This behavioral intention is usually affected by subjective norms which pertaining to behavior and/or attitudes towards the behavior of individual. 
Contrast idea illustrated by (Becker \& Ulstad, 2007), stated that Impression management among student may impact the relationship between biological gender and ethics whenever using and dealing with computers.

With all the above literature, the following hypothesis are established:

2.1 H1: There is a significant difference between Impression Management (IM) and position hold.

2.2 H2: There is a significant difference between Personal Attributes (PA) and position hold.

2.3 H3: There is a significant difference between Degree of Hardcore Pirate (DHP) and position hold.

2.4 H4: There is a significant difference between Pirating Behavior (PB) and position hold.

2.4.1 H4a: There is a significant difference between Software uploaded and position hold.

2.4.2 H4b: There is a significant difference between Software downloaded and position hold.

2.4.3 H4c: There is a significant difference between Software shared and position hold.

2.4.4 H4d: There is a significant difference between Software received and position hold.

2.4.5 H4e: There is a significant difference between Medium used and position hold.

2.4.6 H4f: There is a significant difference between Frequency doing piracy (per week) and position hold.

2.4.7 H4g: There is a significant difference between Frequency doing piracy (last month) and position hold.

2.4.8 H4h: There is a significant difference between Frequency doing piracy (last year) and position hold.

2.5 H5: There is a significant difference between Reciprocal Fairness (RF) and position hold.

2.6 H6: There is a significant difference between Procedural Fairness (PF) and position hold.

2.7 H7: There is a significant difference between Perceptions (P) and position hold.

2.8 H8: There is a significant difference between Subjective Norms (SN) and position hold.

2.9 H9: There is a significant difference between Intention (I) and position hold.

2.10 H10: There is a significant difference between Ethical Standards (ES) and position hold.

2.10.1 H10a: There is a significant difference between Copyright Infringement and position hold.

2.10.2 H10b: There is a significant difference between Materials Used (i.e. graphics) and position hold. 
2.10.3 H10c: There is a significant difference between Feeling guilty for pirating and position hold.

2.10.4 H10d: There is a significant difference between Feeling commercialized pirated software and position hold.

2.10.5 H10e: There is a significant difference between Feeling not to be disciplined and position hold.

2.10.6 H10f: There is a significant difference between Feel worried about legal repercussions and position hold.

2.10.7 H10g: There is a significant difference between Feeling purchasing pirated software and position hold.

\section{Methodology}

\subsection{Instrument and Method}

The instrument used for collecting the data was questionnaire. The questionnaire is adapted and adopted from (Liu \& Fang, 2003; Becker \& Ulstad, 2007; Siegfried, n.d.; Hinduja, 2003; Namlu \& Odabasi, 2007 and Anwar, Bahry \& Amran, 2012). However, some modification is made to suit and cater the environment setting. The questionnaire is divided into 11 parts, where part A captures information on demographic, part B to part $\mathrm{K}$ capture information for measuring the independent and dependent variables. Items used in Part A were 8 questions, Part B were 20 questions, Part $\mathrm{C}$ were 16 questions, Part D and $\mathrm{E}$ were 8 questions each, Part $\mathrm{F}$ and $\mathrm{G}$ were 2 questions each, Part $\mathrm{H}$ were 30 questions, Part I and $\mathrm{J}$ were 3 questions each and Part $\mathrm{K}$ were 7 questions. Overall there are all together 107 items used in the questionnaire.

All measures for the variables were using several scale style. As Part B using likert scale with seven extremes with 1 for "Not True" and 7 for "Very True", Part C using semantic differential scale, Part D, F, G, H, I, J were using likert scale with five extremes with 1 for "Strongly Disagree", 2 for "Disagree", 3 for "Undecided / Neutral", 4 for "Agree" and 5 for "Strongly Agree", Part E using combination of "Yes" and "No" and number of frequency and Part K same as part E using likert scale with five extremes with 1 for "Strongly Disagree", 2 for "Disagree", 3 for "Undecided / Neutral", 4 for "Agree" and 5 for "Strongly Agree" and "Yes" and "No".

\subsection{Instrument and Method Population and Sampling}

This study was conducted among information professionals in Klang Valley, Malaysia such Federal Territory of Kuala Lumpur and Shah Alam area. Basically, they are working in across business functions. This study is using simple random sampling, 400 questionnaires were distributed to these information professionals. 384 questionnaires were returned, however 190 questionnaires were found unusable after data cleaning is made and 194 for data analysis. Statistical Package for the Social Sciences version 20 is used to analyze the data. 


\section{1) Macrothink}

\section{Results and Discussion}

\subsection{Respondents Profiles}

Table 1 presents the respondent's demographic profile. Looking to the gender, $56 \%$ of the respondents are male and $44 \%$ are female. Majority of the respondents are age between $20-$ 30 years old while the minority i.e. 6 out of 194 is less than 20 years old. In term of education, 57 were diploma holder, 32 were SPM/MCE and STPM/ Matriculation holder each, 27 were degree holder, 20 were SRP/PMR holder, 15 were specialization certificate holder and 6 were Master holder.

Table 1. Respondent's Demographic Profile

\begin{tabular}{llcc}
\hline $\begin{array}{l}\text { Characteristics } \\
\text { Items }\end{array}$ & & Frequency & Percentage \\
\hline Gender & Female & 85 & $44 \%$ \\
& Male & 109 & $56 \%$ \\
Age (years) & Less than 20 & 6 & $3 \%$ \\
& $20-30$ & 107 & $55 \%$ \\
& $31-40$ & 69 & $36 \%$ \\
& More than 40 & 12 & $6 \%$ \\
& SRP/PMR & 20 & $10 \%$ \\
& SPM/MCE & 32 & $16 \%$ \\
Educational & STPM/ Matriculation & 32 & $16 \%$ \\
& Specialization Certificate & 15 & $8 \%$ \\
& Diploma & 57 & $29 \%$ \\
& Degree & 27 & $14 \%$ \\
& Master & 6 & $3 \%$ \\
& PhD & 0 & $0 \%$ \\
& Others & 5 & $3 \%$ \\
\hline
\end{tabular}

Demographic Profile: Gender, Age and Education level.

\subsection{Analysis}

Data level of measurement used in variables such Impression Management (IM), Personal Attributes (PA), Degree of Hardcore Pirate (DHP), Reciprocal Fairness (RF), Procedural Fairness (PF), Perceptions (P), Subjective Norms (SN) and Intention (I) were ordinal and we transform it into scale. While, variables such Pirating Behavior (PB) and Ethical Standards (ES), remain unchanged which nominal and ordinal. To measure the objective of the study, any variables fall under data level of measurement is scale, the statistical test used is ANOVA while the rest is using Kruskal Wallis Test. 
Table 2. ANOVA Analysis

Impression Management

\begin{tabular}{llllll}
\hline & Sum of Squares & df & Mean Square & F & Sig. \\
\hline Between Groups & 13.781 & 7 & 1.969 & 3.251 & 0.003 \\
Within Groups & 112.643 & 186 & 0.606 & & \\
Total & 126.424 & 193 & & & \\
\hline
\end{tabular}

Personal Attributes

\begin{tabular}{llllll}
\hline Between Groups & 1.797 & 7 & 0.257 & 0.959 & 0.463 \\
Within Groups & 49.779 & 186 & 0.268 & & \\
Total & 51.576 & 193 & & & \\
\hline
\end{tabular}

Degree of Hardcore Pirate

\begin{tabular}{llllll}
\hline Between Groups & 25.463 & 7 & 3.638 & 4.927 & 0.000 \\
Within Groups & 137.335 & 186 & 0.738 & & \\
Total & 162.799 & 193 & & & \\
\hline
\end{tabular}

Reciprocal Fairness

\begin{tabular}{llllll}
\hline Between Groups & 8.818 & 7 & 1.260 & 1.535 & 0.158 \\
Within Groups & 152.620 & 186 & 0.821 & & \\
Total & 162.438 & 193 & & & \\
\hline
\end{tabular}

Procedural Fairness

\begin{tabular}{llllll}
\hline Between Groups & 11.569 & 7 & 1.653 & 1.707 & 0.110 \\
Within Groups & 180.051 & 186 & 0.968 & & \\
Total & 191.620 & 193 & & & \\
\hline
\end{tabular}

Perceptions

\begin{tabular}{llllll}
\hline Between Groups & 3.584 & 7 & 0.512 & 2.206 & 0.036 \\
Within Groups & 43.174 & 186 & 0.232 & & \\
Total & 46.758 & 193 & & &
\end{tabular}

Subjective Norms

\begin{tabular}{llllll}
\hline Between Groups & 7.035 & 7 & 1.005 & 1.558 & 0.150 \\
Within Groups & 119.962 & 186 & 0.645 & & \\
Total & 126.997 & 193 & & & \\
\hline Intention & & & & & \\
\hline Between Groups & 19.157 & 7 & 2.737 & 2.810 & 0.008 \\
Within Groups & 181.117 & 186 & 0.974 & & \\
Total & 200.273 & 193 & & & \\
\hline
\end{tabular}


Table 3. Kruskal Wallis Test Analysis

Test Statistics ${ }^{a, b}$

Pirating Behavior

\begin{tabular}{|c|c|c|c|c|c|c|c|c|}
\hline & E1 & E2 & E3 & E4 & E5 & E6 & E7 & E8 \\
\hline Chi-Square & 23.787 & 28.560 & 14.900 & 15.239 & 7.571 & 10.152 & 10.497 & 10.627 \\
\hline Df & 6 & 6 & 6 & 6 & 6 & 6 & 6 & 6 \\
\hline Asymp. Sig. & 0.001 & 0.000 & 0.021 & 0.018 & 0.271 & 0.118 & 0.105 & 0.101 \\
\hline \multicolumn{9}{|c|}{ Ethical Standards } \\
\hline & $\mathrm{K} 1$ & $\mathrm{~K} 2$ & K3 & & K4 & K5 & K6 & K7 \\
\hline Chi-Square & 11.895 & 9.47 & 17 & & 9.864 & 9.431 & 4.735 & 19.348 \\
\hline Df & 6 & 6 & 6 & & 6 & 6 & 6 & 6 \\
\hline Asymp. Sig. & 0.064 & 0.14 & 0.0 & & 0.130 & 0.151 & 0.578 & 0.004 \\
\hline
\end{tabular}

a. Kruskal Wallis Test

b. Grouping Variable: Position 
Table 4. Summary of the Analysis Hypothesis

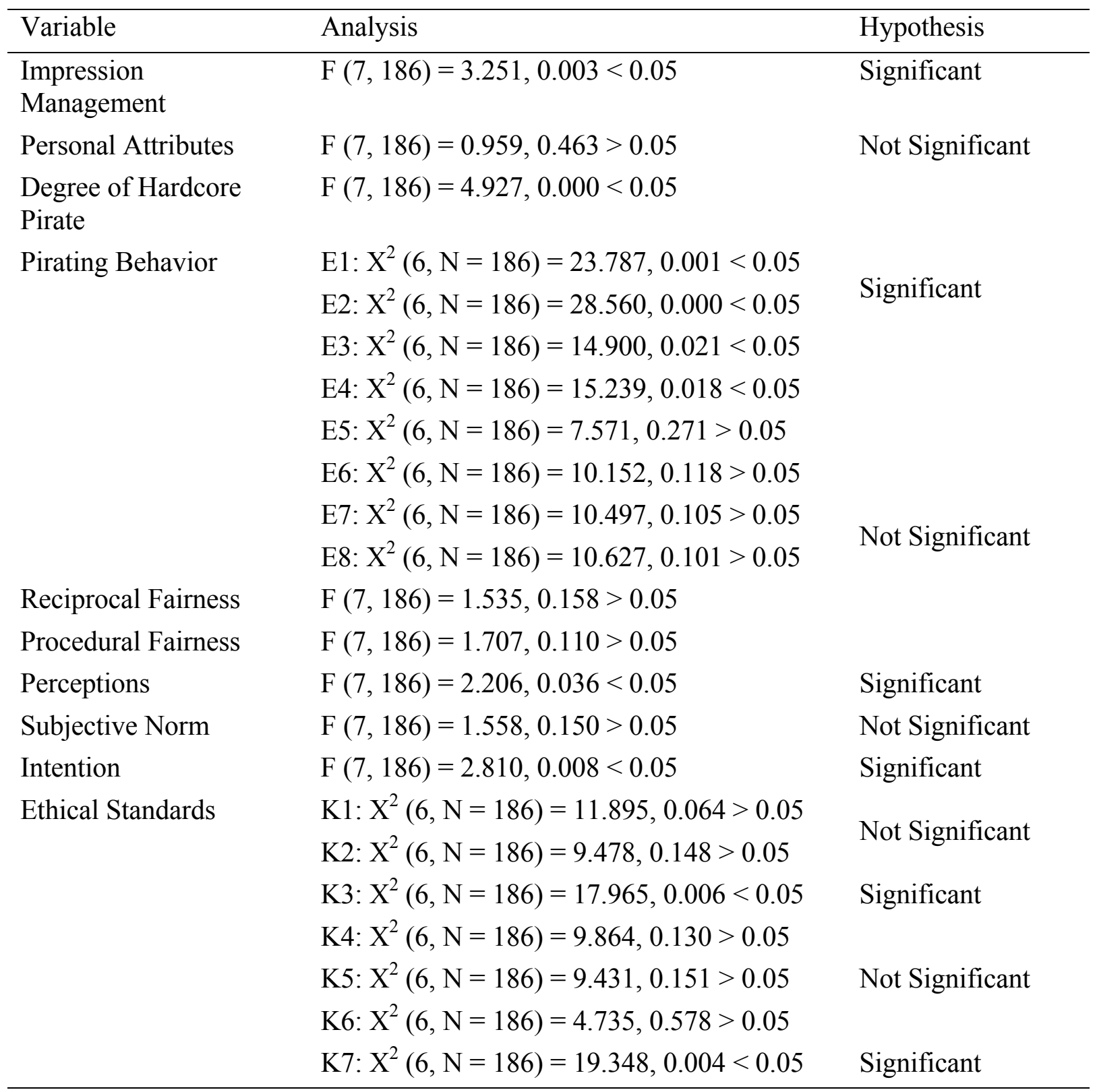

Table 2 and 3 presents the output of the analysis while Table 4 presents the summary of the analysis hypothesis. It can be reported that factors such Impression Management (IM), Degree of Hardcore Pirate (DHP), Perceptions (P) and Intention (I) were significant difference with position hold among information professionals. Mean while, factors such Personal Attributes (PA), Reciprocal Fairness (RF), Procedural Fairness (PF) and Subjective Norms (SN) were not significant difference with position hold among information professionals. However, items E1, E2, E3 and E4 were significant difference and items E5, E6, E7 and E8 were not significant difference with position hold for factor Pirating Behavior (PB). Factor for Ethical Standards (ES) reported that items K3 and K7 were significant difference and items $\mathrm{K} 1, \mathrm{~K} 2, \mathrm{~K} 4, \mathrm{~K} 5$ and $\mathrm{K} 6$ were not significant difference. 


\section{Conclusion and Recommendation}

Any reasons behind choosing, downloading and using pirated software may due to several factors. Studies conducted across the world also look into several areas. As study conducted by Mun (2013), he investigated on the impact of various national factors, i.e. nation's economic, technological and industry- specific capabilities and found that the present piracy phenomenon in the international market is complex and multi-faceted. Another study conducted Liu \& Fang (2003), they measured what are the cause and effect of relationship between morality and ethical decision-making from using software piracy using structural equation model (SEM) and the study shows that there is a positive correlation between factors, i.e. religious beliefs, moral evaluation, ethical judgment and behavioral intention. Similar study related with behavior among tertiary done by Namlu \& Odabasi (2007) and the output of the study indicate that the students are comprehend and appreciate the global issues in computer ethics however they also suggested to further study on behavior to reach ethical solutions in computer technologies. Nevertheless, the use of pirated software is highly dependent with the individual ethical. With the advancement of technologies and the wide range of internet, individual has choice to choose. This issues never been solved and yet the number of using it is rising year by year. What mechanism that suitable can be filtered out with the collaboration and cooperation worldwide. Perhaps future study can measure, find out and proposed the right mechanism to reduce this issue.

\section{Acknowledgement}

Thanks to Research Management Institute (RMI), Universiti Teknologi MARA (UiTM) for providing us with the financial assistance to make the research possible (Project code: 600-RMI/DANA 5/3/RIF (707/2012). Besides RMI, our thanks are also dedicated to all respondents in Federal Territory of Kuala Lumpur and Shah Alam area for their quick and fast respond of the questionnaire deserved more than a word of thank.

\section{References}

Anwar, N., Bahry, F. D. S., \& Amran, N. (2012). Installation and Use of Pirated Software: The Factors Behind It. Proceeding of Business, Engineering and Industrial Applications (ISBEIA), 207-212.

Becker, D. A., \& Ulstad, I. (2007). Gender Differences in Student Ethics: Are Females Really More Ethical? Plagiary: Cross Disciplinary Studies in Plagiarism, Fabrication, and Falsification, 77-91.

Haque, A., Rahman, S., \& Khatibi, A. (2010). Factors Influencing Consumer Ethical Decision Making of Purchasing Pirated Software: Stuctural Wquation Modeling on Malaysian Consumer. Journal of International Business Ethics, 3(1), 30-40.

Hinduja, S. (2003). Trends and patterns among online software pirates. Ethics and Information Technology, 5, 49-61. http://dx.doi.org/10.1023/A:1024910523384

Liu, L-P. \& Fang, W-C. (2003). Ethical Decision-Making, Religious Beliefs and Software Piracy. Asia Pacific Management Review, 8(2), 185-200. 


\section{Macrothink}

Journal of Management Research

ISSN 1941-899X

2015, Vol. 7, No. 2

Loch, K. D., \& Conger, S. (1996). Evaluating Ethical Decision Making and Computer Use. Communications of the ACM, 7(39), 74-83. http://dx.doi.org/10.1145/233977.233999

Mastura, J., Thurasamy, R., \& Tee, W. T. (2008). The Intention to Use Pirated Software: A Study of Undergraduate Students in a Public Instituation of Higher Learning in Malaysia. Problems and Perspectives in Management, 6(2), 4-12.

Mun, S-H. (2013). Reality Check: Rethinking the Global Software Piracy Problem. International Telecommunications Policy Review, 20(2), 1-26.

Namlu, A. G., \& Odabasi, H. F. (2007). Unethical computer using behavior scale: A study of reliability and validity on Turkish university students. Computers \& Education, 48, 205-215. http://dx.doi.org/10.1016/j.compedu.2004.12.006

Siegfried, R. M. (n.d.). Student Attitudes on Software Piracy and Related Issues of Computer Ethics. Retrieved from http://home.adelphi.edu/ siegfried/ETIN2004.pdf on 13 March 2013.

\section{Copyright Disclaimer}

Copyright for this article is retained by the author(s), with first publication rights granted to the journal.

This is an open-access article distributed under the terms and conditions of the Creative Commons Attribution license (http://creativecommons.org/licenses/by/3.0/). 